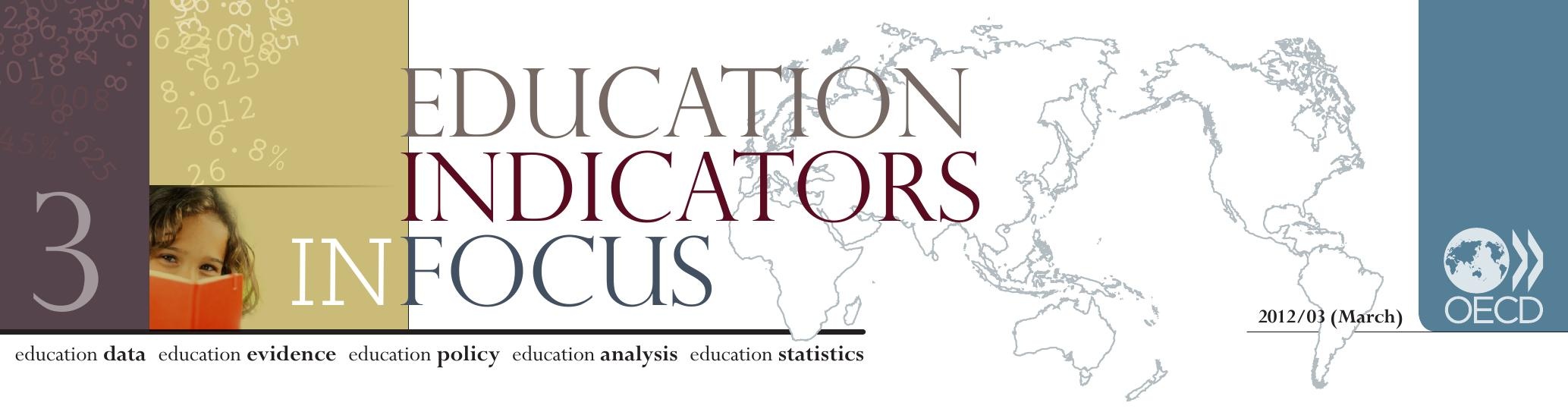

\title{
How are girls doing in school - and women doing in employment - around the world?
}

- On the 2009 PISA reading assessment, girls outperformed boys in every country, and on average by 39 score points - the equivalent of one year of schooling. By contrast, boys tend to outperform girls in mathematics.

- An estimated $66 \%$ of young women in OECD countries are expected to enter a university programme during their lifetime, compared to $52 \%$ of young men.

- Men are more likely than women to hold advanced research qualifications, and $74 \%$ of all graduates in the fields of engineering, manufacturing and construction are men.

- Higher (tertiary) education improves job prospects for both men and women, and the gender gap in employment narrows at the highest levels of educational attainment.

Throughout the world, girls are outperforming boys in reading...

As the world marks the achievements of women this month, the progress of girls and young women in education - and of women in employment - can't be denied. In recent years, the achievement gap between boys and girls in school has narrowed in key subjects - so much that in some areas, the focus of concern is now on the underachievement of boys. For example, on the 2009 PISA reading assessment, 15-year-old girls outperformed boys in every OECD country, and on average by 39 points - the equivalent of one year of school. On the 2009 PISA mathematics assessment, 15-year-old boys tend to perform slightly better than girls in most countries, while in science, patterns of performance related to gender are less pronounced.

... and women are in the majority among entrants to higher education.

The better girls and boys do in school, the more likely they are to continue in education. Between 2000 and 2009, the likelihood that both young men and women will enter a university (tertiary-type A) programme increased dramatically, from $47 \%$ to $59 \%$. However, when these results are broken down by gender, it's clear that women are driving these increases. For instance, the proportion of women who are expected to enter a university programme rose from $51 \%$ in 2000 to $66 \%$ in 2009 , while the proportion of men who are expected to enter these programmes rose from $42 \%$ in 2000 to $52 \%$ in 2009 .

Across OECD countries, the proportion of women who hold a university-level qualification now equals or exceeds that of men in 29 of the 32 countries for which data are comparable. On average, $59 \%$ of all graduates who held a first university degree in 2009 are women; this proportion is below $50 \%$ only in China, Japan, Korea and Turkey. 


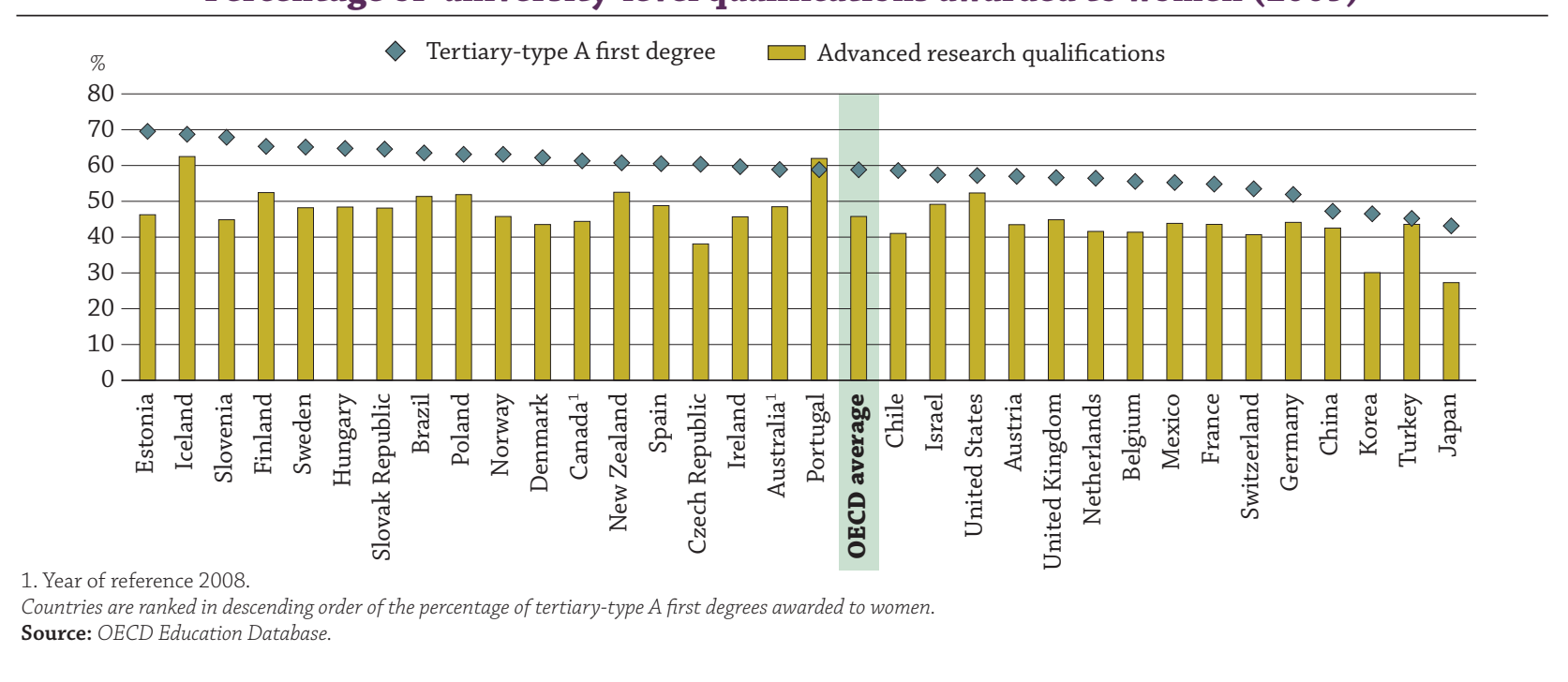

However, men are more likely than women to earn a doctorate...

At the same time, women remain under-represented the very highest levels of education. In $2009,54 \%$ of advanced research qualifications such as doctorates were awarded to men, on average across OECD countries. This pattern is visible in all countries except Brazil, Finland, Iceland, New Zealand, Poland, Portugal and the United States, where women now earn the majority of advanced qualifications. In Japan and Korea, only about 30\% of advanced research qualifications are awarded to women.

... and women are under-represented in some fields of education. Moreover, some fields of study are still branded as "masculine" or "feminine". In 2009, in every OECD country except Japan and Turkey, more than $70 \%$ of higher education students in the field of education were women. On average across OECD countries, $75 \%$ of the degrees awarded in the field of health and welfare also went to women. By contrast, in most countries, fewer than $30 \%$ of all graduates in the fields of engineering, manufacturing and construction were women.

In a handful of countries, gender imbalances in some traditionally male-dominated fields of study are beginning to shrink. For example, in the Czech Republic, Germany and the Slovak Republic, the proportion of women graduating with science degrees grew by more than 10 percentage points between 2000 and 2009. As a result, these countries are now closer to the OECD average of $40 \%$ - a figure that has remained stable over the past decade. In 2000, the European Union announced a goal to increase the number of university graduates in mathematics, science and technology by at least $15 \%$ by 2010 , and to reduce the gender imbalance in these subjects. So far, however, progress toward this goal has been marginal.

\section{Women's gains in education are helping to narrow the gender gap in employment in many countries...}

Overall, however, the strong progress of women in education is translating into positive outcomes in the labour market. In 2009, an average of 79\% of women with a higher education qualification were employed, compared to $66 \%$ of women with an upper secondary qualification, and $46 \%$ of women without an upper secondary qualification. Notably, women are still less likely than men to participate in the labour market - even when they have the same qualifications - and are also more likely to work part-time. 


\section{Percentage of tertiary degrees awarded to women, by field of education (2009)}

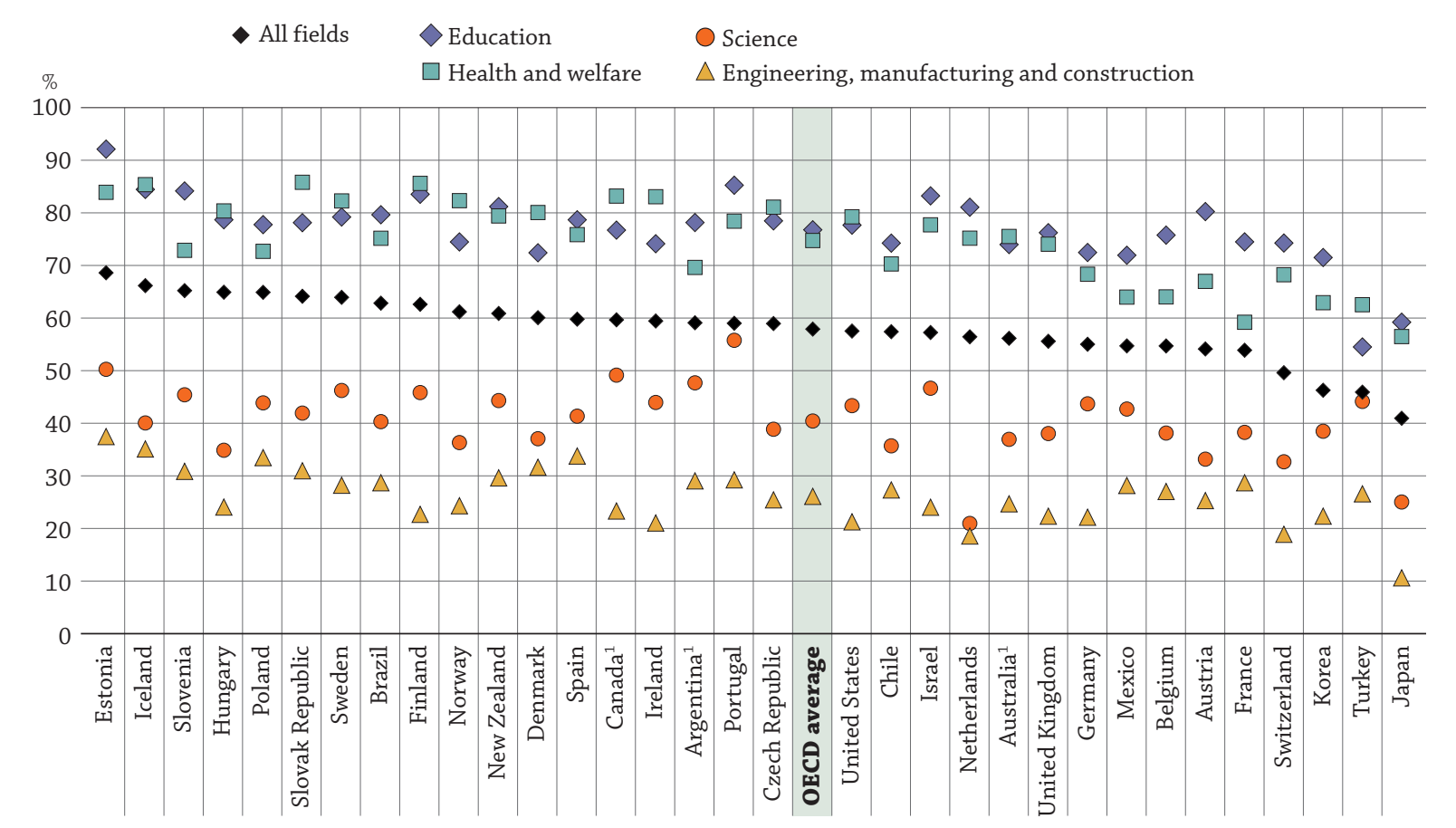

1. Year of reference 2008 .

Countries are ranked in descending order of the percentage of tertiary degrees awarded to women in 2009.

Source: OECD. Argentina: UNESCO Institute for Statistics (World Education Indicators Programme). Education at a Glance 2011 : OECD Indicators, Indicator A4 (www.oecd.org/edu/eag2011).

However, the gap in favour of men has shrunk in the decade since 2000, and is much less pronounced at higher levels of education. For instance, the gender gap in employment narrowed from 25 percentage points in 2000 to 21 percentage points in 2009 among those without an upper secondary qualification, and from

19 percentage points in 2000 to 15 percentage points in 2009 among those with an upper secondary qualification. And it's narrower still among those with a higher education qualification, decreasing from 11 percentage points in 2000 to 9 percentage points in 2009.

These figures can vary widely across countries: among people without an upper secondary qualification, the gender gap in employment is less than 10 percentage points in Finland, Iceland and Norway, but more than 40 percentage points in Chile, Mexico and Turkey. Among people with a higher education qualification, the gender gap in employment tends to narrow significantly in all OECD countries except Japan, Korea, Mexico and Turkey, where it exceeds 15 percentage points.

... and so are recent initiatives that promote gender equality in employment.

OECD countries are doing more to reduce gender gaps in employment, too. For example, in the Nordic countries, Germany and Portugal, fathers can receive a parental leave entitlement and income support during the leave period. In Iceland, Norway and Spain, some firms are required to have at least $40 \%$ of their boardroom seats assigned to women, depending on the size of the company and the number of board members. Similar initiatives have been introduced in Belgium, France, Italy and the Netherlands. Meanwhile, other companies, such as Deutsche Telekom, have introduced voluntary quotas for women in management and family-friendly practices such as flex-time and tele-working. 


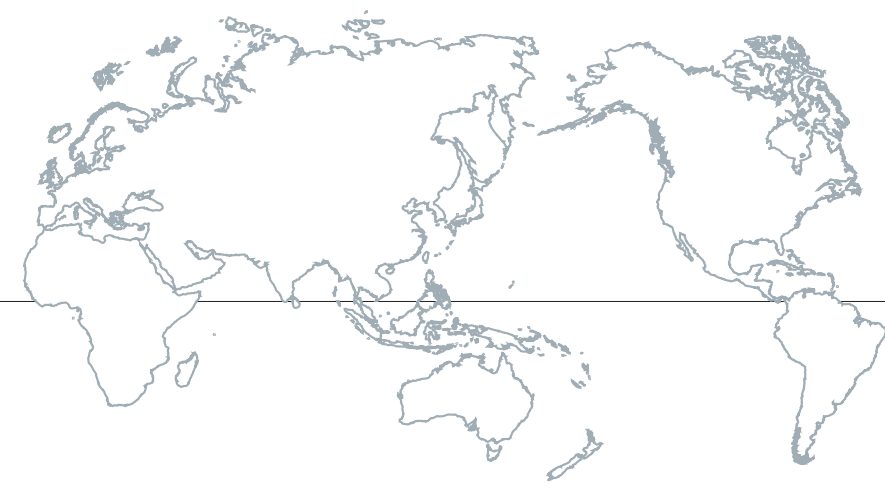

Employment rates, by gender and level of educational attainment (2009)

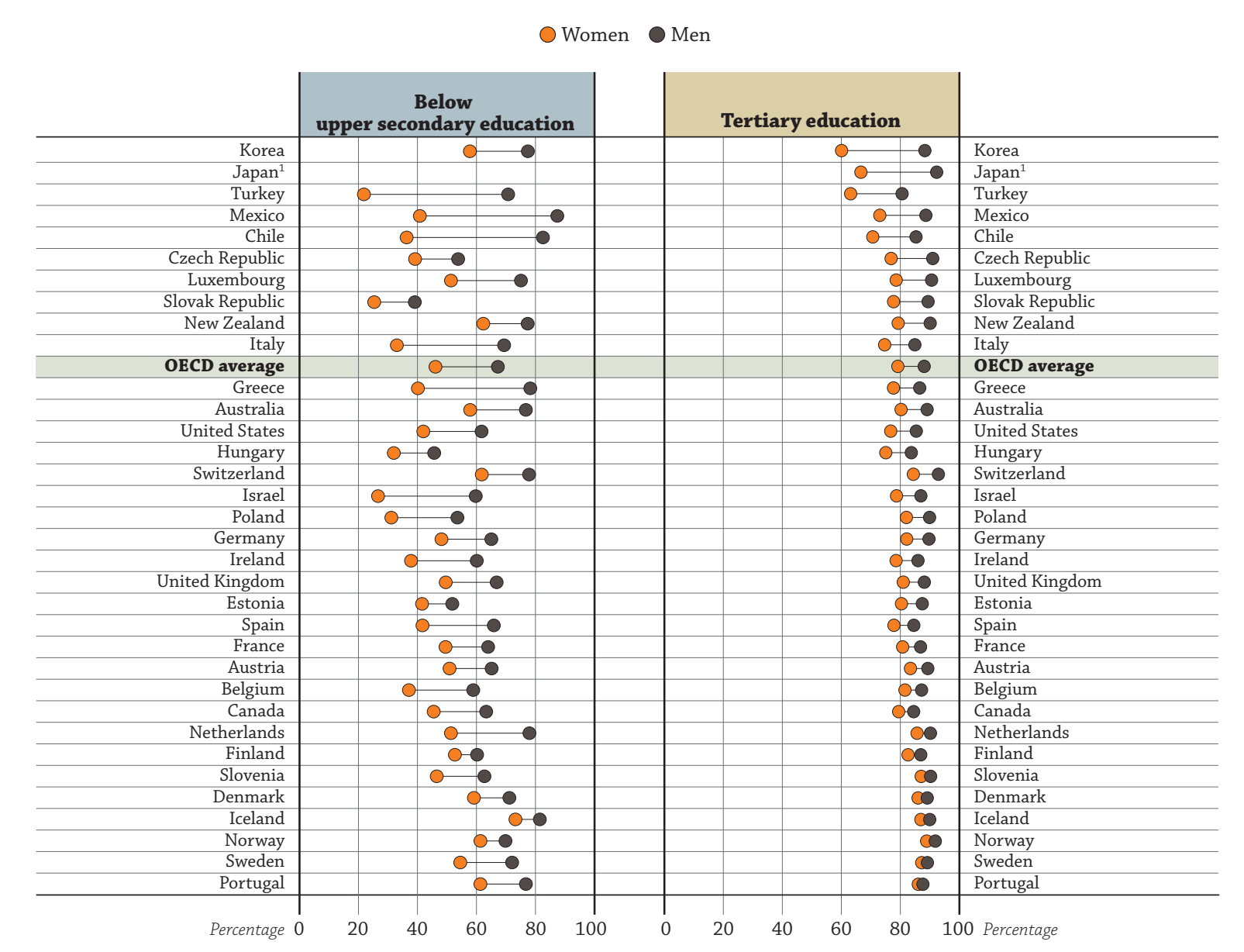

1. Data for below upper secondary education are missing.

Countries are ranked in descending order of the gender gap in employment rates for individuals with tertiary education.

Source: Education at a Glance 2011 : OECD Indicators, Indicator A7 (www.oecd.org/edu/eag2011).

All these initiatives are recent and still widely debated. They merit further analysis to understand their benefits in terms of women's employment outcomes and company performance.

The bottom line Efforts to increase mathematics and science performance among girls - as well as reading achievement among boys - can promote gender equality even further in education. Meanwhile, initiatives to break down gender stereotypes in fields of study and progressive corporate policies can increase women's employment opportunities. 